\title{
No fio da navalha: os desafios do trabalho profissional do assistente social no sistema socioeducativo
}

\author{
On the razor's edge: the challenges of the professional work of the social worker in the socio- \\ educational system \\ Bruna Carolina Bonalume* \\ Adriana Giaqueto Jacinto** \\ Lindsay Lemos Gonçalves Ferreira***
}

Resumo: 0 presente artigo tem como objetivo propor reflexões teóricas acerca das tensões e contradições que atravessam o trabalho dos assistentes sociais no contexto da socioeducação. Isso porque é preciso reconhecer que mesmo inscrito no circuito das garantias processuais, previstas pelo ECA e pelo SINASE, o Sistema Socioeducativo situa-se em uma estreita relação com instituições historicamente marcadas pelo conservadorismo, hierarquização e poder, cuja incorporação de estratégias de controle, através da combinação de instrumentos de repressão e punição, legitimam um legado. Superar esse traço histórico, ainda se constitui como um desafio. Assim, as reflexões suscitadas neste texto analisam os paradigmas que emanam do caráter sancionatório e punitivo do sistema socioeducativo e permeiam o cotidiano profissional em um tempo presente marcado pela retração dos direitos sociais.

Palavras-chave: Socioeducação. SINASE. Repressão. Trabalho. Serviço Social.

Abstract: This article aims to propose theoretical reflections on the tensions and contradictions that cross the work of social workers in the context of socio-education. This is because it is necessary to recognize that even inscribed in the circuit of procedural guarantees, foreseen by ECA and SINASE, the Socio-Educational System is located in a close relationship with institutions historically marked by conservatism, hierarchy and power, whose incorporation of control strategies, through the combination of instruments of repression and punishment, legitimize a legacy. Overcoming this historical trait is still a challenge. Thus, the reflections raised in this text analyze the paradigms that emanate from the sanctioning and punitive character of the socio-educational system and permeate the professional routine in a present time marked by the retraction of social rights.

Keysword: Socio-education. SINASE. Repression. Work. Social Work

\footnotetext{
* Doutoranda no Programa de Pós Graduação em Serviço Social na UNESP de Franca.

** Doutora em Serviço Social pela Universidade Estadual Paulista - UNESP/Franca.

*** Mestranda no programa de pós graduação em Serviço Social da Faculdade de Ciências Humanas e Sociais da Universidade Estadual Paulista UNESP.
} 


\section{Introdução}

Adentrar no terreno árido da socioeducação é um grande desafio, tendo em vista um tempo presente marcado pelo desenfreado avanço neoliberal e seus rebatimentos na condição de vida dos sujeitos sociais, sobretudo da população jovem. Temos visto no país a intensificação dos debates em torno da redução da maioridade penal e o crescente discurso burguês, que alinhado à ideologia dominante, fortalece a lógica tutelar, moralista e punitiva, ao passo que nas fronteiras da subalternidade situam-se esses jovens, estereotipados pela periculosidade e pela identidade marginal, experimentando os mais perversos impactos da violação de direitos e da (des) proteção social.

Nessa trama social, econômica, política e cultural, o Sistema Socioeducativo situa-se em uma estreita relação com instituições historicamente marcadas pelo conservadorismo, hierarquização e poder, cuja incorporação de estratégias de controle, através da combinação de instrumentos de repressão e consenso, legitimam um legado. Não se pode ainda desconsiderar que não raras vezes essas instituições são atravessadas pelo sucateamento, diante do desmonte dos recursos públicos, fato somado à precarização das condições de trabalho dos agentes socioeducativos, orientadores sociais e todo corpo de trabalhadores.

Com base nisso, no presente artigo serão tecidas discussões construídas na perspectiva de contextualizar a emergência do SINASE, os inegáveis avanços do sistema socioeducativo, mas não ignorando o fato das contradições que emergem da dinâmica neoliberal, permeada por uma ideologia dominante. Assim, as reflexões aqui suscitadas trazem à tona os desafios do trabalho profissional do assistente social na socioeducação diante de um cenário de retração dos direitos sociais, avanço dos discursos ultraconservadores que tendem à criminalização sobretudo das juventudes pobres, negras e periféricas. Discutir o trabalho profissional, em um cenário tão complexo e contraditório, implica trazer à tona o compromisso com a efetivação de um trabalho alicerçado na perspectiva crítica e no enfrentamento dos modelos tradicionais de viés conservador/moralizante.

\section{O trabalho do assistente social na sociabilidade do capital}

Para pensarmos o trabalho do assistente social, inicialmente, é preciso compreender o trabalho no seu sentido ontológico, como constituinte do ser social. Nessa direção Marx 
(2013) esclarece de forma inequívoca que a categoria trabalho resulta do intercâmbio orgânico entre o homem e a natureza, um processo de transformação mútua à medida que através do trabalho o homem garante tanto a sua existência humana como também sua constante reprodução social, ao passo que sua ação também modifica a natureza. Podemos assim considerar que o trabalho está na gênese da mediação entre homem e natureza, relação esta determinante, portanto, para o desenvolvimento do ser social na medida em que é a partir desta mediação que os homens desenvolvem historicamente as condições de produção e reprodução social com a objetivação de suas necessidades. Para Marx (2013, p. 261) o trabalho é uma condição de existência do homem, independentemente de todas as formas de sociedade, que reside na condição "universal do metabolismo entre homem e natureza, perpétua condição natural da vida humana".

Tendo como base o referencial marxista, Granerman (2009, p. 4) destaca que a compreensão dessa dimensão ontológica do trabalho também implica em reconhecer que as relações sociais tecidas pela humanidade ao longo de sua história, "sempre se assentaram no trabalho como fundamento da própria reprodução da vida, dado que, por meio de tal atividade, produziram os bens socialmente necessários a cada período da história humana".

Todavia, o trabalho em sua dimensão ontológica, inscrito na esfera de produção capitalista, ganha outras configurações, diferentes daquelas que o definem como trabalho concreto, produtor de valor de uso, isso porque passa a compor a esfera produtiva do capitalismo, convertendo-se, então, em trabalho abstrato. Importante assinalar que enquanto o trabalho concreto possui um caráter útil para sobrevivência e atendimento das necessidades humanas e sociais em todas as formas de sociedade, cujo valor reside no caráter de uso, o trabalho abstrato, segundo Rubin (1980, p.156) "expressa determinadas relações entre os homens no processo de produção" mercantil e, portanto, produz valores de troca, que segundo o autor, consequentemente resultará na "indiferença do produtor para com seu trabalho concreto" (p. 161)

Dessa forma, o trabalho torna-se instrumento de subordinação e dominação do capital, na medida em que consegue impor a venda, o assalariamento e a exploração da força de trabalho. Tal fato ocorre porque na lógica capitalista tem-se o controle sobre a força de trabalho, assim como sobre os meios de produção. Mas o que está no centro dessa discussão 
é de que maneira isso atravessa a vida do trabalhador? Quais as consequências do domínio do capital sobre as relações sociais entre as classes?

Nessa direção corroboramos com lamamoto (2015, p. 50), quando a autora afirma que "todo espaço ocupado pelo capital transforma-se em espaços de poder". E como espaço de poder, essa subordinação ao capital nos marcos do modo de produção capitalista sinaliza que estamos diante de uma sociedade que legitima a exploração de uma classe sobre a outra e coloca a classe trabalhadora em condição de subalternidade e luta diária pela sobrevivência, controla e reproduz a desigualdade social, naturaliza e criminaliza o processo da pobreza. As consequências desta exploração são profundas, resultando, sobretudo, na intensificação das expressões da questão social e num verdadeiro abismo que coloca de um lado uma pequena burguesia detentora dos meios de produção e da riqueza socialmente produzida e do outro uma massa pauperizada formada principalmente pela classe trabalhadora.

Podemos, assim, afirmar que as desigualdades sociais, consolidadas nesse modelo vigente de sociedade, são resultado da riqueza socialmente produzida e acessada por poucos. A pobreza alastra-se, ao passo que aumenta a distância entre ricos e pobres no Brasil, o que denuncia uma realidade, na qual a ampliação das riquezas contrasta fortemente com o aprofundamento da miséria e com isso, o crescente processo de pauperização, insegurança, violência, precarização e exploração do trabalho vão se tornando traços permanentes e integrantes dessa sociedade dividida em classes.

Com base nas discussões Mészáros (2002), podemos afirmar que o capitalismo do tempo presente tem como marco o seu esgotamento. A crise estrutural propagada a partir dos anos 1970 se aprofunda ao passo que nos aproximamos da barbárie. Segundo Paulo Netto (2010, p. 31) o sistema sociometabólico capitalista "administra" a barbárie e todas as suas formas de manifestação, como a miséria, a pobreza, o desemprego estrutural, entre tantas outras, pois precisa garantir a expansão e acumulação crescente do capital. São tempos difíceis, onde vivemos intimamente expostos às atrocidades da expansão neoliberal, de forma violenta em sua mais perversa face, contexto esse que nos remete às palavras de Rosa Luxemburgo (1999) "socialismo ou barbárie", frase que foi complementada por Mészáros (2003, p. 108-109), "socialismo ou barbárie se tivermos sorte". Para o autor esse complemento dado à frase de Luxemburgo, tem como propósito sinalizar os novos perigos 
que atravessam o tempo presente, nesse sentido destaca que "o extermínio da humanidade é um elemento inerente ao curso do desenvolvimento destrutivo do capital".

As afirmações postas pelos autores nos apontam que estamos imersos ao caos, ao dramático e desastroso ciclo do capital em sua mais pungente face e nos revela o quanto a legitimação e expansão capitalista atravessa de todas formas as dimensões da existência humana. Temos, desta forma, um contexto marcado pelo (des) financiamento das políticas sociais, a mercantilização em seu estágio universal, o culto ao individualismo, a banalização da violência a partir de discursos de ódios que se propagam, sobretudo em direção às adolescências e juventudes pobres, negras e periféricas, a esse contexto soma-se, ainda, um ultraconservadorismo que se reedita e se fortalece na cena contemporânea.

É no bojo desse debate que demarcamos o trabalho do assistente social. Segundo lamamoto (2009) o Serviço Social emerge como profissão inserida na divisão sociotécnica do trabalho profundamente relacionada com o agravamento da questão social, em um determinado contexto sócio-histórico, marcado pelo capitalismo monopolista, cujas contradições emanam da relação capital e trabalho. Nesse contexto, esclarecem lamamoto e Carvalho $(2006$, p. 77$)$ que a questão social "não é senão as expressões do processo de formação e desenvolvimento da classe operária e de seu ingresso no cenário político da sociedade, exigindo seu reconhecimento como classe por parte do empresariado e do Estado" Imersa na consolidação do sistema social de produção e atravessada por interesses de classes claramente antagônicos, a profissão se institucionaliza no marco da regulação estatal das políticas sociais públicas como resposta do Estado frente à situação de pauperização da classe trabalhadora. Nesses termos, é preciso reconhecer que os espaços sócio ocupacionais do Serviço Social são perpassados por contradições que condensam e confrontam "concepções, valores, intencionalidades, propostas de sujeitos individuais e coletivos, articulados em torno de distintos projetos em disputa no espaço institucional onde se implementam políticas públicas". (RAICHELIS, 2010, p. 752)

Isso porque não podemos ignorar o fato de que o Estado brasileiro historicamente vem atendendo ao projeto da burguesia, ou seja, de reprodução do capital, enquanto mantem de forma mínima, a sobrevivência das classes subalternas. Assim, os direitos sociais são subordinados à lógica orçamentária e a política social à política econômica. A cidadania e as 
necessidades humanas são rebaixadas ao nível da sobrevivência física, prevalecendo o conceito de mínimos sociais na oferta de direitos. (IAMAMOTO, 2015).

Segundo Behring (2008, p.64) as políticas sociais, em tempos de disputa pelo fundo público, tornam-se cada vez mais sucateadas, restritivas, paternalistas e nessa perspectiva "deixam de ser direito social", caracterizando uma espécie de "clientelismo (pós) moderno". Aliado ao minimalismo das políticas sociais emerge, o fenômeno da criminalização da questão social (IANNI, 1991) que, segundo o autor, tende a transformar as manifestações da questão social em problemas de assistência social ou em objeto de segurança e repressão.

Com base nessas considerações, podemos afirmar que o trabalho do assistente social nos espaços sócio-ocupacionais que compõem a área sociojurídica ${ }^{1}$, dentre esses a socioeducação- objeto de discussão do presente artigo, ganha centralidade, pois se traduz numa constância de desafios cotidianos frente ao contraditório papel do Estado e pelas tensões próprias do modo de produção capitalista.

Desta forma, o trabalho profissional na área sociojurídica se dá diante de um Estado que constrói estruturas fortemente hierarquizadas, as quais resultam, não raramente, em práticas de cunho autoritário e que caminham, portanto, na contramão da defesa do Projeto Ético Político da profissão. Esses mecanismos coercitivos são apontados pelo CFESS (2014, p. 15) como necessários à "manutenção da ordem social - marcada pelas contradições de classes". Além disso, o poder de interferir e decidir sobre a vida das pessoas, de outras instituições, de populações ou até mesmo de países, a partir do uso da força física ou da lei, confere a tais instituições características extremamente violadoras de direitos - mesmo quando o discurso que as legitima é o da garantia dos direitos (CFESS, 2014, p. 16).

Nesse sentido, as requisições postas ao Serviço Social, neste contexto, tendem a revelar a necessidade de produzir práticas punitivas, de criminalização da pobreza e à sustentação do perverso modelo da ordem vigente do capital.

\footnotetext{
${ }^{1}$ A área Sociojurídica, define-se como um conjunto de espaços sócio-ocupacionais onde atuam tanto os assistentes sociais, como também outros profissionais de áreas afins e operadores do Direito, nos quais as atribuições privativas e as competências são mediadas pelo universo jurídico e pelo Direito. (BORGIANI, 2014, p. 16-17)
} 


\section{A Emergência do Sistema Nacional de Atendimento Socioeducativo: um campo de disputa contraditório}

Ao revisitar a trajetória sócio-histórica da justiça juvenil brasileira ficamos diante de duas faces de uma mesma moeda. De um lado os inegáveis avanços do ECA, no que se refere ao reconhecimento de crianças e adolescentes como sujeitos de direitos, sua inserção no circuito dos direitos humanos, bem como a superação do paradigma menorista e a adoção da Doutrina de Proteção Integral. Do outro, porém, não podemos adotar a postura ingênua e messiânica de ignorar que essa luta está inscrita numa dinâmica neoliberal, permeada por uma ideologia dominante de exploração e profundas desigualdades sociais. Mesmo tendo decorridos 30 anos da promulgação do ECA, ainda permanecemos atônitos diante da velha questão que coloca o adolescente e o jovem brasileiro entre a escassa proteção e o devasso controle repressivo.

No que se refere aos atos infracionais cometidos por adolescentes o ECA avançou nas tratativas e garantias processuais, muito embora Frassetto et al. (2012) destacam que até meados dos anos 2000, pouco havia se avançado no atendimento de adolescentes e jovens em conflito com a lei. Segundo os autores, o cenário era caótico.

\footnotetext{
As medidas privativas de liberdade eram executadas em unidades superlotadas, centralizadas, insalubres - tristes condições desnudadas por pesquisas e matérias jornalísticas eventuais - mas, sobretudo, por recorrentes episódios de rebeliões e mortes nas instituições. As medidas em meio aberto, por seu turno, salvo poucas exceções, ou seguiam sendo oferecidas de forma errática por entes estaduais, com baixa capilaridade e baixa integração com a rede local, ou estavam entregues à responsabilidade das prefeituras, sem compromisso de cofinanciamento e apoio técnico para implantação, implementação e capacitação de pessoal. (FRASSETTO, et al. 2012, p. 20)
}

Mesmo diante disso, Frassetto, et al. (2012) destacam que prevaleceu a convicção, por parte das instâncias federais, de que não caberia mudar a lei, o caso era de se apostar no modelo do Estatuto, agregando esforços para sua implantação, antes de se pensar em modificar a sua lógica. Segundo Saraiva (2012) as mobilizações para a elaboração de uma lei específica para execução de medidas socioeducativas começam a se dar já nos anos 1990. Em 1999, foi criada uma comissão na ABMP (Associação Brasileira de Magistrados, Promotores de Justiça e Defensores Públicos da Infância e da Juventude) responsável pela elaboração de um anteprojeto de lei que gerou a aprovação de uma Resolução no âmbito do CONANDA 
(Resolução n. 119/06, primeiro ato normativo que dispôs sobre o Sistema Nacional de Atendimento Socioeducativo) e também o Projeto de Lei (PL) n. 1627/07, aprovado e convertido na Lei Federal n. 12.594/2012. (SARAIVA, 2012).

Esse breve relato nos revela que decorreram, entre a promulgação do ECA e a Resolução 119/06, 16 anos e outros 6 até a Lei 12. 594/ 2012, ou seja, um espaço de tempo considerável, tendo em vista que as fragilidades existentes nas tratativas, sobretudo da execução das medidas socioeducativas, já eram reconhecidas no início dos anos 1990.

O SINASE é um instrumento composto por um “[...] conjunto ordenado de princípios, regras e critérios, de caráter jurídico, político, pedagógico, financeiro e administrativo, que envolve desde o processo de apuração de ato infracional até a execução de medida socioeducativa". Trata-se, portanto, de uma política pública intersetorial voltada à garantia de direitos de adolescentes que venham cometer atos infracionais. (BRASIL, 2006, p. 22). A Lei 12.594, em art. 1으 §2으, define três objetivos referentes às medidas socioeducativas:

I - a responsabilização do adolescente quanto às consequências lesivas do ato infracional, sempre que possível incentivando a sua reparação; II - a integração social do adolescente e a garantia de seus direitos individuais e sociais, por meio do cumprimento de seu plano individual de atendimento; e III - a desaprovação da conduta infracional, efetivando as disposições da sentença como parâmetro máximo de privação de liberdade ou restrição de direitos, observados os limites previstos em lei. (BRASIL, 2012)

Para Frassetto et al. (2012, p. 27) há um aspecto positivo na definição dos objetivos para todas as medidas socioeducativas uma vez que isso se constitui "em um poderoso referencial de interpretação de todo o documento, com impacto que atravessa desde o planejamento mais geral da gestão, até o atendimento direto e específico de um adolescente". Todavia, atentam os autores para a sincronia dos objetivos com Código Penal e a Lei de Execuções Penais.

No inciso III do §2을 do art. 1으, ao se referir à desaprovação da conduta infracional, há claro paralelismo como o art. 59 do Código Penal, e sua regra de que a pena deve ser aplicada de acordo com o necessário para a reprovação do crime. O mesmo dispositivo traz também similitudes importantes com os artigos 1 ㅇ e 3 o da lei de execuções penais, nos quais se reafirma como objetivo da execução penal a efetivação das disposições da sentença e o asseguramento de que todos os direitos não afetados por ela ou pela lei. (FRASSETTO et al., 2012, p. 28) 
Para os autores, as medidas carregam em si uma natureza penal, mesmo que a Lei pretenda algo distinto, avaliam que os objetivos acima descritos tornam-se insuficientes para neutralizar o discurso da penalidade e o caráter punitivo agregados às medidas. Segundo Sposato (2006, p. 254) torna-se importante destacar "que o reconhecimento do caráter penal e sancionatório da medida socioeducativa não retira a tarefa e o desafio pedagógico que se colocam para a Justiça da Infância e Juventude e para os programas de atendimento socioeducativo". A essa afirmação, consideramos importante acrescentar as reflexões feitas por Costa (2015) ao reconhecer, ainda, que os aspectos sancionatórios e pedagógicos das medidas necessitam ser explicitados à luz da organização cultural das sociedades. Para a autora:

Quando se critica o aspecto punitivo da medida socioeducativa e se reivindica o aspecto pedagógico que a mesma deve ter, está se deixando de colocar em relevo que tipo de modelo de educação a sociedade ocidental adota na formação de suas gerações. Pois, nesta sociedade, educar é repassar os valores aceitos socialmente de uma geração para outra e tais valores devem ser inculcados através da coerção e do consenso. (COSTA, 2015, p. 67)

Nesse sentido, há de se reconhecer que mesmo diante de avanços no tocante às práticas pedagógicas e educativas, ainda prevalece no conjunto da sociedade a crença de que se educa, se corrige o comportamento das pessoas pela aplicação dos castigos, das punições. Nessa mesma direção Nicodemos (2006) destaca que medida socioeducativa, ainda que idealizada com base em um construto pedagógico, reveste-se de coerção e sanção.

Para o autor, o cerne desse debate está no processo de criminalização e revela que há em curso um controle social exercido pelo Estado, o qual se sustenta pela criminalização dirigida para os grupos economicamente não integrados ao sistema de produção do Estado capitalista. Para Nicodemos (2006, p. 62) “a criminalização por meio das ações estatais é fato emergente e inegociável para o interesse da sociedade burguesa". Destaca que esse processo apresenta três níveis de efetivação de um sistema, "que objetivamente vê no direito penal não só um ramo de normas jurídicas dentro de um sistema normativo maior, mas sim um aliado a serviço de um interesse politicamente definido." Evidentemente essa lógica terá desdobramentos no trato do Estado com os adolescentes e jovens que cometem atos infracionais e consequentemente no modo como gerencia o Sistema Socioeducativo. 
O primeiro nível do processo de criminalização instaura-se a partir da produção da norma, à medida que segundo o autor há formas distintas de reconhecimento dos direitos, o que implica também em entender que "o processo de aplicação da norma penal não se efetivará obedecendo à lógica do Estado Liberal de igualdade entre todos os cidadãos". (NICODEMOS, 2006, p. 63)

Assim, cabe aqui o questionamento: a quem se destina o Sistema Socioeducativo?

A pergunta nos leva a contextualizar o abismo, que segundo Nicodemos (2006) há entre o que foi proposto pela norma estatutária (ECA e SINASE) e a realidade social de adolescentes e jovens, sobretudo aqueles criminalizados pelo Estado brasileiro, tendo em vista que é sobre a população pobre, negra e favelada que recairá o braço punitivo do Estado. Segundo dados do Levantamento Anual do SINASE, (Brasil, 2018), referente ao ano de 2015, o recorte étnico-racial dos adolescentes e jovens em cumprimento de medida socioeducativa de internação é elucidativo e nos revela que não parece tratar-se apenas de uma mera eventualidade que $61,03 \%$ são adolescentes e jovens negros que estão inseridos nesses espaços. Por isso, corroboramos com os estudos de Adorno (2003), que ao discutir a relação entre justiça, igualdade jurídica e juízo, sob o ponto de vista da influência do racismo e dos preconceitos raciais na distribuição da justiça penal, conclui que embora o crime não seja cometido apenas pela população negra, a punição, sim, é voltada a esse grupo.

O segundo nível reside na agenda de investimento para a política de desenvolvimento do Estado brasileiro. Segundo Nicodemos (2006, p. 64), não há no tempo presente uma direção estatal no sentido de reverter o quadro de profundas desigualdades sociais que atingem a população infanto-juvenil, portanto, "excluída do sistema econômico da política estatal, passam então a integrar o exército de milhões de brasileiros que serão negativamente etiquetados como potenciais criminosos". Por fim, o terceiro nível do processo de criminalização se dá em torno do "sistema de responsabilização do adolescente autor de ato infracional" o que inclui também as medidas socioeducativas, uma vez que essas contribuíram para a cristalização da imagem de infrator. (NICODEMOS, 2006, p. 64).

O SINASE institui princípios para a execução das medidas socioeducativas, sendo esses: legalidade, excepcionalidade, prioridade a práticas ou medidas de caráter restaurativo, proporcionalidade, brevidade, individualização, mínima intervenção, não discriminação e fortalecimento dos vínculos familiares e comunitários no processo socioeducativo. Cabe 
considerar que esses princípios previstos no Art. 35 do SINASE devem ser interpretados, conforme orienta o art. 24 dessa mesma Lei, em harmonia com os princípios da doutrina da proteção integral, previstos pelo ECA, quais sejam: o da dignidade da pessoa humana, o da prioridade absoluta, o da condição peculiar da criança e do adolescente como pessoas em desenvolvimento e o do melhor interesse da criança e do adolescente. (BRASIL, 2012)

Nesse sentido, os princípios da brevidade, da excepcionalidade e da intervenção mínima, já anteriormente instituídos pelo ECA foram reafirmados pela Lei do SINASE. O princípio da excepcionalidade da intervenção judicial e da imposição de medidas (judiciais), leva em consideração não só as medidas privativas de liberdade, mas sim uma excepcionalidade da própria imposição de qualquer medida socioeducativa e tem como objetivo evitar a banalização da intervenção do Estado em situações cotidianas da vida do adolescente e do jovem em cumprimento de medidas socioeducativas e de sua família.

Isso nos permite ainda afirmar que as medidas em meio aberto (LA e PSC) devem ser priorizadas em detrimento das medidas que restringem total ou parcialmente a liberdade de adolescentes e jovens, todavia, contraditoriamente, o que observamos é o crescente percentual de meninos e meninas que se somam à massa encarcerada brasileira. Rizzini, et.al. (2019, p. 73) ao analisarem dados dos Relatórios de Guias Expedidas por Tribunais de Justiça Estaduais (Cadastro Nacional de Adolescentes em Conflito com a lei), constataram que houve uma pequena tendência "no aumento de expedição de guias para cumprimento de MSE em meio fechado, entre 2016-17, o que pode ser interpretado como sinal de agravamento na decisão sobre aplicação de medidas".

O Levantamento Anual do SINASE (BRASIL, 2018) destacou que essa tendência de aumento no número de adolescentes Jjovens em privação ou restrição da liberdade no Brasil é histórica e em um período de seis anos aumentou $58,6 \%$. Segundo o relatório no ano de 2009, havia 16.940 adolescentes\jovens cumprindo alguma medida desse tipo (internação, internação provisória e semiliberdade) e, em 2010 esse número atingiu um aumento de 4,5\% com 17.703. Já em 2011, esse número sobe para 19.595 adolescentes\jovens, ou seja, um aumento de 10,5\%. Em 2013, essas medidas atingem novo aumento, 11,7\%, o que significa dizer que naquele ano 23.066 adolescentes Jjovens estavam privados ou com a liberdade restrita. Em 2015 essa marca atinge 26.868, desses 18.381 adolescentes Jjovens que cumpriam 
a medida de internação (68\%), 2.248 estavam em semiliberdade (9\%) e 5.480 em internação provisória (23\%).

O Estado que mais encarcera essa população é o Estado de São Paulo, com 9.918 meninos e meninas nos espaços da Fundação CASA. Em seguida, está o Rio de Janeiro com 2.235 e Minas Gerais com 1.963. Os dados tornam-se ainda mais alarmantes quando atentamos para a superlotação das unidades de internação no Brasil. Segundo dados levantados pelo Conselho Nacional do Ministério Público (BRASIL, 2019, p. 23-24), o Brasil dispõe hoje de 16.161 vagas para adolescentesไjovens em instituições de cumprimento da medida socioeducativa da privação da liberdade, contudo, entre os meses de agosto e setembro de 2018, havia 18.086 adolescentes e jovens nesses espaços, ou seja, um déficit de 1925 vagas.

Podemos dizer que os dados caminham na contramão dos discursos que disseminam a necessidade de ampliar os mecanismos de punição diante de uma suposta 'impunidade' com o sistema de responsabilização trazido pelo ECA, pois o que temos visto é o crescente e violento processo de encarceramento das adolescências e juventudes, o que se alinha profundamente ao que Wacquant (2001) afirmou ser um Estado Penal em detrimento do Estado Social. Para o autor, o primeiro componente do Estado Penal refere-se à transformação das políticas sociais em instrumentos de controle e vigilância, sobretudo da população pobre e considerada como perigosa. O segundo componente é o encarceramento ou a repressão ofensiva sobre essa mesma população, que atinge prioritariamente negros e jovens moradores da periferia. Wacquant (2001, p. 31) aponta que a força desse segundo componente tem como traço característico o avanço neoliberal, que envolve a visível diminuição do orçamento das políticas sociais em detrimento do crescente orçamento das políticas penais/criminais.

Portanto, podemos dizer que a expansão do Estado Penal alinhada ao projeto neoliberal, conservador e de cunho repressivo, fortalece o fetiche da proteção integral sobre as juventudes, ao passo que silencia as contradições que emanam da (des) proteção social, da fragilidade das políticas públicas e da maneira perversa de controle e reprodução das desigualdades sociais engendradas no sistema capitalista.

Como consequência dessa direção ideológica de punição e repressão, a medida socioeducativa acaba por se revestir de um caráter assistencial curativo, termo cunhado por 
Silva (2011). Para a autora, embora as medidas tenham uma pretensiosa dimensão socioeducativa, na verdade estão travestidas pelas expressões do controle sociopenal em torno das adolescências e juventudes que cometem atos infracionais, o que demonstra "o quanto o ECA tem sido utilizado, em larga medida, como o Código Penal é utilizado para o adulto" (SILVA, 2011, p. 161).

Para a autora são esses mecanismos de controle social e ideológico, associados à forma histórica de atenção aos adolescentes \jovens que cometem atos infracionais irão configurar o controle sociopenal. Como então pensar a socioeducação?

Segundo Rizzini et.al. (2019, p. 36)) o conceito de socioeducação emerge dos princípios da pedagogia social e traz à tona um novo paradigma que visa superar a lógica menorista e da mera penalização de adolescentes e jovens. Para os autores, o conceito e os elementos que compõem a socioeducação na cena contemporânea ainda se mostram "nebulosos". Isso porque ainda estão presentes "representações e práticas que criminalizam os mesmos, como no passado". Além disso, atentam os autores para a ausência de definições específicas em relação ao que de fato constituiu a natureza sociopedagógica das medidas socioeducativas.

Dito isto, concordamos com Santos (2020, p. 198) quando a autora afirma que dadas às condições sócio-históricas nas quais emerge a política de atendimento socioeducativo no Brasil, a função "político-social da socioeducação" pode ser entendida a partir de duas condições que estão relacionadas entre si e são essas: "1) a função mistificadora da (re) educação (e demais ilusões "re"); 2) a função - concreta, mas implícita - de contenção e gestão das vidas matáveis". Isso porque, ao passo que temos uma lacuna no que concerne de fato ao caráter político, ético e pedagógico da socioeducação, temos também o incremento nas formas de controle sociopenal que propaga a violência e torna legítima a matança de adolescentes e jovens.

Nessa mesma direção Jimennez, et al., (2012, p. 3- 5) tecem a crítica sobre a Lei, alertando para o fato de que essa lacuna, deixada pela ausência de parâmetros pedagógicos mais definidos e consistentes, abre espaço para as antigas práticas de disciplinamento e dos rígidos padrões autoritários. Esclarecem que essa questão não se resume a um problema de caráter pedagógico, mas possui uma natureza política, uma vez que "ao suprimir a perspectiva educativa, que desejaríamos ver alcançada, introduz certo nível de flexibilidade que permite 
poder ser interpretada como política neoliberal ao deixar espaços livres para a continuidade de práticas tradicionais, arcaicas e repressivas". Os autores ainda destacam que no SINASE a finalidade dos processos educativos é tratada de forma secundária, à medida que há uma omissão no que se refere à concepção de socioeducação e parâmetros pedagógicos em detrimento de uma valorização de procedimentos administrativos de uma "racionalidade técnico-burocrática contida nas normas e regulamentos para a sua implantação".

Eis que estão postos os desafios para o trabalho profissional do assistente social na socioeducação brasileira!

\section{Serviço Social e socioeducação: uma reflexão necessária}

A socioeducação é também um campo de atuação para o assistente social, pois relembrando brevemente a história, notamos que este profissional sempre atuou no sistema de justiça juvenil brasileiro.

\footnotetext{
Através do modelo de "casos individuais", buscava-se no dito "menor" e em suas famílias, com frequência consideradas imorais, as causas para a autoria das infrações análogas a crimes, compreendidas como patologias oriundas tanto de progressões genético- hereditárias, quanto vinculadas a desajustes sociais e morais. As diversas expressões da questão social vivenciadas por crianças, adolescentes e famílias pobres eram assim, reduzidas a problemas individuais, que deveriam ser tratados física, moral e socialmente (CELESTINO, 2016, p. 194).
}

Como elucida Celestino, a atuação profissional ocorria na perspectiva de culpabilizar, moralizar, ajustar ao meio as crianças, adolescentes e suas famílias. Infelizmente, ainda hoje observamos em alguns lugares esse tipo de atuação no ambiente socioeducativo. Com a promulgação do Estatuto da Criança e do Adolescente e posteriormente do SINASE (Sistema Nacional de Atendimento Socioeducativo) e consequentemente um novo "modelo" de socioeducação, observamos que a atuação do assistente social se realiza na tensão entre a punição e a proteção.

[...] estes permanecem com a difícil tarefa de promoção, defesa e garantia de direitos de adolescentes, que, sentenciados como autores de atos infracionais, passam a ser alvo de invertidas pautadas na criminalização e violação de direitos, justificadas diante do ato infracional cometido (CELESTINO, 2016, p. 206).

Assim, são muitos os desafios encontrados pelo assistente social na socioeducação, neste artigo apresentamos alguns deles. Não temos a intenção de culpabilizar o profissional 
que lá atua, visto que é importante lembrar que o assistente social, como coloca lamamoto (2015, p. 421) também é um trabalhador assalariado, que vende sua força de trabalho em troca de um salário para sobreviver; estamos inseridos nesta perspectiva neoliberal em que todos os dias vemos o aumento das expressões da questão social, entre elas, o desemprego, a precarização do trabalho, dos serviços, das instituições e o adoecimento físico e mental dos trabalhadores.

\begin{abstract}
Essa dinâmica de flexibilização/ precarização atinge também o trabalho do assistente social, nos diferentes espaços institucionais em que se realiza, pela insegurança do emprego, precárias formas de contratação, intensificação do trabalho, aviltamento dos salários, pressão pelo aumento da produtividade e de resultados imediatos, ausência de horizontes profissionais de mais longo prazo, falta de perspectivas de progressão e ascensão na carreira, ausência de políticas de capacitação profissional, entre outros. (RAICHELIS, 2011, p. 422).
\end{abstract}

O assistente social, como o adolescente que comete ato infracional e é encaminhado para cumprir uma medida socioeducativa, também sofre uma violação de seus direitos, tendo muitas vezes que se "adequar" aos limites institucionais para manter o emprego, mesmo tendo consciência que isso vai contra o projeto ético político e Código de Ética da profissão.

Feitas essas breves considerações, passemos ao objetivo desse artigo, ressaltando que escolhemos discorrer sobre três desafios encontrados pelo assistente social no campo da socioeducação. Esses foram escolhidos porque são as ditas "atribuições" do Serviço Social no ambiente socioeducativo, independente de ser uma medida de meio aberto ou fechado, são eles: atendimento ao adolescente, atendimento à família e contato/ encaminhamento com/à a rede socioassistencial.

\title{
Atendimento de novo pra quê, se nada muda: a dificuldade em compreender o adolescente em sua singularidade.
}

Iniciamos esse tópico com uma fala comum dos adolescentes em medida socioeducativa: "Para que ter atendimento novamente se muitas vezes o que ouvem não faz sentido para eles, ou se o que dizem, não são ouvidos?" Na medida socioeducativa, os profissionais (não só o assistente social) têm metas para serem cumpridas, sendo uma delas o atendimento individual ao adolescente (pelo menos um por semana pela Psicologia e duas vezes por mês pelo Serviço Social), no caso da Fundação CASA, no estado de São Paulo. Os atendimentos são realizados, mas se questiona: Há qualidade nesses? Ou são apenas para 
cumprir metas, protocolos, não se levando em consideração a singularidade do adolescente? Nesses atendimentos dialogamos com o adolescente, escutamos suas histórias de vida, além do cometimento do ato infracional, ou ainda muitas vezes queremos impor nossa visão de mundo, nossos valores?

Souza (2019, p. 83) traz que ao "contar a história desta juventude desde o início de sua história individual (e social), contabilizando as inúmeras violações de direitos que esta população vem sofrendo desde a infância, a nossa compreensão sobre a juventude em conflito com a lei pode ser diferente". Ou seja, no atendimento com o adolescente, precisamos entender que o ato infracional não é a história de vida dele, foi apenas um "acontecimento/ episódio", que o fez se tornar um adolescente da socioeducação.

Nos atendimentos, na maioria das vezes, aborda-se a história de vida do adolescente, mas superficialmente, sem aprofundar, talvez devido às diversas demandas que aparecem nos atendimentos, como por exemplo, a questão comportamental, disciplinar, que ainda é muito forte, como se o adolescente fosse apenas o seu "bom comportamento" dentro da instituição e este o critério principal para que ele seja desligado da medida. Não podemos deixar de citar as práticas violentas e agressões que ainda acontecem nas medidas de meio fechado.

Outro ponto a ser colocado em relação ao atendimento ao adolescente é a questão do projeto de vida: Realiza-se o Plano Individual de Atendimento (PIA), todavia, em muitos casos foca-se apenas no mercado de trabalho, como se o "trabalho" fosse a melhor solução para o adolescente não infracionar novamente, o que reforça ainda mais a socioeducação na mercadologia neoliberal.

A percepção comum e vigente de estabelecimento de um padrão, modelo esperado, do adolescente/ jovem estudioso, que ingressará no mercado de trabalho (mesmo que precário) e que não entrará em conflito com a Lei, mesmo considerando que o contexto é diverso e complexo (BONATTO, 2019, p. 96).

Além do mercado de trabalho, quando "o adolescente não tem idade para trabalhar" as metas do PIA muitas vezes relacionam-se com a escola (como dever e não como direito) e a cursos profissionalizantes básicos, não se observando as aptidões do adolescente também para as áreas de arte/cultura, esporte, entre outras.

\section{A família não adere ao atendimento: culpabilização da família pelo sucesso ou fracasso da medida socioeducativa.}


Esse segundo item traz em seu enunciado uma fala comum entre os profissionais: "A família não adere ao atendimento". Quando pensamos nessa situação, estamos culpabilizando a família pelo fracasso da medida socioeducativa, estamos indo contra o artigo 227 da Constituição Federal que diz "É dever da família, do Estado e da Sociedade assegurar os direitos fundamentais da criança e do adolescente", ou seja, não é só a família a responsável pelo adolescente, mas também o Estado e a sociedade, lembrando novamente que $o$ ato infracional é multifatorial.

\footnotetext{
Quando o discurso profissional é aquele que "a família não adere" ou "a família não tem interesse", logo observa-se o perfil positivista conservador do trabalho profissional. É preciso investigar os motivos da dificuldade de adesão, aprofundando as leituras e diálogos para um trabalho social que leve as famílias a compreenderem a sua importância enquanto espaços protetivos na socioeducação do adolescente, fortalecendo-o nesta jornada de auto- avaliação e novo reconhecimento enquanto sujeito social e político. (SILVA, 2020, p. 412).
}

Como menciona Silva (2020) o discurso da "não adesão" é um discurso conservador. O trabalho profissional com vista à emancipação, como trazem o projeto ético político e o Código de Ética do Serviço Social, é um trabalho que tem como objetivo propiciar espaço de escuta e acolhimento, entender as dificuldades que fazem com que aquela família não consiga comparecer nos horários de atendimento individual e em grupo, ou nas visitas ao adolescente. Talvez seja a situação financeira, a dificuldade em deixar os outros filhos com pessoas desconhecidas, ou não ter com quem deixá-los, dificuldade quanto à locomoção (quando é um adolescente de município de fora), violência doméstica, dependências, abandono, entre outros. Para sabermos em profundidade a dificuldade encontrada pela família, é preciso não discriminar, criar vínculo, colocar-se no lugar do outro, saber escutar, como traz Paulo Freire em sua obra Pedagogia da Autonomia:

Aceitar e respeitar a diferença é uma dessas virtudes sem que a escuta não se pode dar. Se discrimino o menino ou menina pobre, a menina ou menino negro, o menino índio, a menina rica, se discrimino a mulher, a camponesa, a operária, não posso evidentemente escutá-las e se não as escuto, não posso falar com eles, mas a eles, de cima para baixo. Sobretudo, me proíbo entendê-los. Se me sinto superior ao diferente, não importa quem seja, recuso-me escutá-lo ou escutá-la (FREIRE, 2002, p. 45)

Assim, entendemos que o trabalho com famílias, como colocado por Freire (2002), envolve a postura de não discriminar, mas saber escutar, numa relação horizontal e não 
vertical (de cima para baixo), onde prevalece apenas a "verdade" do profissional, mas uma relação dialética onde aprendemos e ensinamos, fortalecendo a participação, a compreensão dos seus direitos.

\section{O talento vence jogos, mas só o trabalho em equipe ganha campeonatos: incompletude institucional e o trabalho em rede.}

Nesse item escolhemos uma frase de Michael Jordan que diz "O talento vence jogos, mas só o trabalho em equipe ganha campeonatos". Essa frase mostra a importância do trabalho em equipe, no caso da socioeducação, além da equipe multiprofissional do atendimento socioeducativo (Prestação de Serviços a Comunidade, Liberdade Assistida, Semiliberdade e Internação) precisamos "unir forças" com o Sistema de Garantia de Direitos, também conhecido como rede socioassistencial. No ECA e SINASE há a expressão “incompletude institucional", referindo-se a essa situação, à importância de vários atores, serviços, programas na efetivação com qualidade do trabalho socioeducativo.

O trabalho desenvolvido dentro do sistema socioeducativo adquire uma característica de trabalho em rede. A atuação em rede sugere a criação de uma teia de vínculos, relações e ações entre indivíduos e organizações. Ela é um espaço aberto ao pluralismo de ideias e a diversidade. Neste espaço se produz uma visão compartilhada da realidade, se articulam diferentes tipos de recursos e se conduzem ações de forma cooperada (TRIBUNAL DE JUSTIÇA PARANÁ, 2012, p. 56).

Quando pensamos em trabalho em rede devemos ter claro que este envolve várias políticas, não só a da assistência social, mas a da educação, saúde, segurança pública, habitação, seguridade, criança e adolescente, entre outras. O trabalho em rede deve ser um espaço aberto ao pluralismo de ideias e à diversidade, mas todos unidos no mesmo propósito. Sabemos que existem muitos desafios para a efetivação deste trabalho, sendo um deles a precarização das relações de trabalho, ausência de profissionais nas equipes, muita demanda nos serviços, que não se limitam apenas à socioeducação, disponibilidade, compromisso, condições de trabalho adequadas, em muitos ambientes faltam materiais e instrumentos de trabalho, como salas adequadas para atendimentos individuais e grupais, computador, acesso à internet, entre outros.

Nessa direção, Silva (2020) traz uma contribuição importante para se pensar o trabalho em rede, ao destacar que podemos observar que em muitos serviços de atendimento 
socioeducativo a equipe entende que realiza o trabalho com a rede porque faz contato e encaminha o adolescente e sua família, principalmente quando próximo ao desligamento da medida, mas como o autor traz, não é só encaminhar, mas é também participar do processo, dialogar, compartilhar as responsabilidades e realizar uma avaliação de como foi o atendimento, o que pouco acontece na socioeducação, devido à demanda de trabalho que os profissionais possuem. Desta forma, ocorre que quando se desinterna um adolescente, na maioria das vezes já tem outro entrando no serviço, o que prejudica muito a elaboração de estratégias de atuação e efetivação desse trabalho.

\section{Considerações finais}

O tema abordado neste artigo é complexo, não conseguiríamos esgotá-lo em algumas páginas. Entendemos que o assistente social está no "fio da navalha", porque ao mesmo tempo em que eticamente coloca-se em defesa dos direitos dos adolescentes que cometem ato infracional, também é um trabalhador inserido na ordem capitalista monopolista, onde todos os dias sofre com a precarização do trabalho, com o sucateamento do serviço, regressão em relação aos direitos sociais.

Reconhecemos que com o ECA e o SINASE houveram muitos avanços em relação ao atendimento de adolescentes que cometem ato infracional, mas necessitamos romper com a visão punitivista, coersiva que ainda persiste. É comum em muitos serviços o uso da violência física e psicológica como forma de "controlar" os adolescentes, algo que ainda remete ao Código de Menores (doutrina da proteção irregular).

Em alguns locais ainda tentam eleger "padrões" para os adolescentes e suas famílias, desconsiderando suas singularidades, sem aprofundar em suas trajetórias de vida, na maioria das vezes marcadas por violação de direitos. Ainda é comum discursos de culpabilização da família, negando-se que é a família, a sociedade e o Estado os responsáveis pela efetivação dos direitos fundamentais de crianças e adolescentes, como está previsto no artigo 227 da Constituição Federal de 1988.

Compartilhamos da ideia de Costa (2015, p. 72) que propõe uma pedagogia emancipadora, onde exista diálogo, em que a sanção não seja a primeira alternativa, seja 
descontruída a cultura de violência, do medo, enfim, que os direitos dos adolescentes sejam respeitados e efetivados.

\section{Referências}

ADORNO, Sérgio. Justiça penal é mais severa com os criminosos negros. Entrevista concedida a Alexandre Zarias. Rev. Comciencia, São Paulo, n.49, s/p., 2003. Disponível em: http://www.observatoriodaimprensa.com.br/primeiras-edicoes/nova-edio-da-revistaeletrnica/. Acesso em: 09 de mar. de 2019.

BEHRING, Elaine. Brasil em contra-reforma: desestruturação do Estado e perda de direitos. 2 ed. São Paulo, Cortez, 2008.

BONATTO, Vanessa Petermann. Medidas Socioeducativas em Meio Aberto: as possibilidades e limites da prática do orientador de medida. Dissertação (Mestrado em Educação). Universidade Estadual Paulista Instituto de Biociências, Programa de pós graduação em Educação, Rio Claro, 2019.

BORGIANNI, Elisabete. Prefácio in: FÁVERO, Eunice; GOIS, Dalva Azevedo (orgs). Serviço social e Temas Sociojurídicos: debates e Experiências. Coletânea Nova de Serviço social. Rio de Janeiro: Lumen Juris, 2014, p. 15-17

BRASIL. LEI № 12.594, de 18 de janeiro de 2012. Institui o Sistema Nacional de Atendimento Socioeducativo (Sinase). Diário Oficial da União, Brasília- DF, 19 jan. de 2012.

. Ministério dos Direitos Humanos (MDH) Levantamento Anual SINASE 2015.

Brasília-DF: Ministério dos Direitos Humanos, 2018.

Conselho Nacional do Ministério Público. Panorama da execução dos programas socioeducativos de internação e semiliberdade nos Estados brasileiros. Brasília-DF: Conselho Nacional do Ministério Público, 2019.

CELESTINO, Sabrina. Adolescente e ato infracional: considerações sobre a atuação do assistente social. Rev. O Social em Questão, Rio de Janeiro, v. 19, n. 35, p. 193- 210, 2016.

CONSELHO FEDERAL DE SERVIÇO SOCIAL. Atuação dos assistentes sociais no sociojurídico: subsídios para reflexão, Brasília: CFESS, 2014.

COSTA, Cândida da. Dimensões da Medida Socioeducativa: entre o sancionatório e o pedagógico. Rev. Textos \& Contextos, Porto Alegre, v. 14, n. 1, p. 62-73, 2015.

FRASSETTO, Flávio Américo, et al. Gênese e desdobramentos da lei 12594/2012: reflexos na ação socioeducativa. Rev. Bras. Adolescência e Conflitualidade, São Paulo, v.6, p. 19-72, 2012. 
FREIRE, Paulo. Pedagogia da autonomia: saberes necessários à prática educativa. São Paulo: Paz e Terra, 2002.

GRANEMANN, Sara. O processo de produção e reprodução social: trabalho e sociabilidade. In: CFESS (Org.). Serviço Social: direitos sociais e competências profissionais. Brasília, CFESS, 2009, p. 223- 238.

IAMAMOTO, Marilda. Serviço Social em tempo de capital fetiche. 9. Ed. São Paulo: Cortez, 2015.

, Marilda. Serviço Social na cena contemporânea. In: CFESS (Org.). Serviço Social: direitos sociais e competências profissionais. Brasília, CFESS, 2009, p. 15-40.

Marilda; CARVALHO, Raul de. Relações Sociais e Serviço Social no Brasil: esboço de uma interpretação histórico-metodológica. 18. Ed. São Paulo: Cortez, 2006.

IANNI, Octávio. A Questão Social. São Paulo em Perspectiva, São Paulo: Fundação SEADE, v. 5, n. 1, p.1-10, 1991.

JIMENEZ, Luciene. et al. Significados da nova lei do SINASE no sistema socioeducativo. Rev. Brasileira Adolescência e Conflitualidade, São Paulo, v. 6, p. 01-18, 2012.

LUXEMBURGO, Rosa. Reforma ou revolução? São Paulo: Expressão Popular, 1999

MARX, KARL. O capital: critica da economia política: livro I: o processo de produção do capital. São Paulo: Boitempo, 2013.

MÉSZÁROS, Istvan. O século XXI: socialismo ou barbárie? São Paulo: Boitempo, 2003. , Istvan. Para além do capital. São Paulo: Boitempo, 2002

NICODEMOS, Carlos. A natureza do sistema de responsabilização do adolescente autor de ato infracional. In: ILANUD; ABMP, SEDH; UNFPA (Org.). Justiça, Adolescente e Ato Infracional: socioeducação e responsabilização. São Paulo: ILANUD, 2006. p. 61-85

PAULO NETTO, José. Uma face contemporânea da barbárie. Comunicação apresentada no III Encontro Internacional “Civilização ou Barbárie”. Serpa, 2010. [online]. Disponível em: https://pcb.org.br/portal/docs/umafacecontemporaneadabarbarie.pdf. Acesso em: 14 de mar. de 2019.

PODER JUDICIÁRIO DA UNIÃO. Tribunal de Justiça do Paraná. Socioeducação. Paraná, Poder Judiciário da União, 2012.

RAICHELIS, Raquel. O assistente social como trabalhador assalariado: desafios frente às violações de seus direitos. Rev. Serviço Social e Sociedade, São Paulo, n. 107, p. 420- 437, 2011. 
, Raquel. Intervenção profissional do assistente social e as condições de trabalho no Suas. Rev. Serviço Social e Sociedade, São Paulo, n. 104, p. 750-772, 2010.

RIZZINI. Irene, et. al. Adolescências, direitos e medidas socioeducativas em meio aberto. São Paulo: Cortez, 2019.

RUBIN, Isaak Illiche. A teoria marxista do valor. São Paulo: Polis, 1980.

SANTOS, Anne Caroline de Almeida. "Socioeducação": do ideal da educação social ao purgatório das vidas matáveis. Rev. O Social em Questão, v.23, № 46, p. 187-202, 2020.

SARAIVA, João Batista Costa. Legem habemus! O SINASE agora é lei. Rev. Multidisciplinar do Ministério Público, Porto Alegre, v. 1, no. 6, p.64-72, 2012.

SILVA, Ana Bella Pavão. Os Novos "Capitães da Areia" e a atualidade do Estado Penal: uma análise sobre os fundamentos históricos, políticos, econômicos, sociais e culturais do Sistema Socioeducativo brasileiro. Tese (Doutorado em Serviço Social). Universidade Estadual Paulista Faculdade de Ciências Humanas e Sociais, Programa de pós graduação em Serviço Social, Franca, 2020.

SILVA, Maria Liduina de Oliveira. Entre proteção e punição: o controle sociopenal dos adolescentes. São Paulo: Editora UNIFESP, 2011

SOUZA, Juliana Cavicchioli de. Medidas Socioeducativas em Meio Aberto: a compreensão de jovens autores de ato infracional. Dissertação (Mestrado em Educação). Universidade Estadual Paulista Instituto de Biociências, Programa de pós graduação em Educação, Rio Claro, 2019.

SPOSATO, Karyna Batista. Princípios e garantias para um direito penal juvenil mínimo. In: ILANUD; ABMP; SEDH; UNFPA (Org.) Justiça, adolescente e ato infracional: socioeducação e responsabilização. São Paulo: ILANUD, 2006, p. 247-276.

WACQUANT, Loic. As prisões da miséria. Rio de Janeiro: Jorge Zahar, 2001. 